\title{
Seasonal Changes in Size Composition of Skipjack Catches in Izu Islands
}

\author{
Muhammad Zainuri, ${ }^{* 1}$ Masao Nemoto, ${ }^{* 1}$ Masahiko Mohri, ${ }^{* 2}$ \\ and Shoichi Takeuchi*1
}

(Received June 7, 1993)

\begin{abstract}
The skipjack catch in the Izu Islands region were classified into 2 groups with a body weight of small (B.W. $\leqq 2.4 \mathrm{~kg}$ ) and large (B.W. $>2.4 \mathrm{~kg}$ ) size. Here, the small size was dominant, showing $82 \%$ of the total catch during the period from 1982 to 1989 . Both the large and the small sizes migrate to Izu Islands region seasonally. In this region the skipjack can be caught throughout the year. During 8 years of fishing operation, the size composition of skipjack taken by Japanese skipjack pole and line fleets differed according to the fishing season. The percentage of catches for the large size was high in the autumn and winter, while a high percentage of the small size occurred from spring to summer. Due to increments in the modal size of skipjack, the small and the large size taken in spring and summer tend to differ in body size from that caught from autumn through winter.
\end{abstract}

Recently, Japanese skipjack landings by pole and line fishery have tended to decrease, although purse seine fishery has been making successful sets for increasing catches. The usually characterized pattern of frequent and quick shifts of fishing grounds for skipjack should be attributed to several different factors including oceanographic, biological, and marketing aspects. The availability of up-to-date information on locating skipjack fishing grounds is therefore essential for successful fishing strategy. For this purpose, particular emphasis should be laid on areas where attempts to introduce skipjack fishing have been successful, due to a lack of information on the body weight composition of the skipjack. In this study the catch tendency of skipjack in the Izu Islands region from 1982 to 1989 is presented, with special reference to seasonal changes in body size composition.

The objective of this study is to determine changes in skipjack catches by size composition in the Izu Islands region based on body weight. This information is one of the most important factors that should be known in connection with the skipiack fishery in the regions. The Izu Islands is one of the Japanese home islands for Islands skipjack fishery. The peak season in this area is from April to July. From 1982 through
1989, the total catch increased from March to May and then decreased until December, while the highest total catch of $25,030.1$ tons was in May.

Skipjack are known to spawn in the western Pacific between lat. $35^{\circ} \mathrm{N}$ and $18^{\circ} \mathrm{S}$ in the northern summer and between lat. $22^{\circ} \mathrm{N}$ and $24^{\circ} \mathrm{S}$ in the northern winter. ${ }^{1)}$ In the adjacent waters of Japan, there are five groups of population structure of skipjack that display life patterns different from each other: the Goto group, a chain group in the Okinawa-Tokara area, a chain group in the Izu-Bonin area, a northeastern inshore group, and a northeastern offshore group. Fish of the "Goto and the northeastern groups" are migratory and their gonads become active in the northern winter, while the gonads of the "chain groups" become active in the northern summer. ${ }^{2)}$ This evidence shows that it is possible for Japanese skipjack pole and line fleets to catch skipjack of heterogeneous size in the Izu Islands region.

\section{Materials and Methods}

This study utilized data from the Tohoku National Fisheries Research Institute: the Annual Report of Effort and Catch Statistics by Area on Japanese Skipjack Baitboat Fishery from 1982

*1 Faculty of Fisheries, Tokyo University of Fisheries, Konan, Minato, Tokyo 108, Japan (Muhammad Zainuri, 根本雅生, 竹内正一: 東京水産大学水産学部).

*2 Shimonoseki University of Fisheries, Nagatahonmachi, Shimonoseki, Yamaguchi 759-65, Japan (毛利 雅彦: 水産大学校). 
through 1989.

Based on the available data, skipjack catches were divided into two groups: small (body weight $\leqq 2.4 \mathrm{~kg}$ ) and large (body weight $>2.4 \mathrm{~kg}$ ) size groups. The distribution of percentage for each group was charted on a latitude-longitude map, on the assumption that changes in position indicated movements of group of each size. Some figures were also presented to show changes in the availability of both groups and skipjack catches per unit of effort during a certain period.

The number of fishing operations is defined as the number of boats conducting fishing operation in the area.

\section{Results}

The catchability of skipjack is often reduced by its distribution, which is scattered in small and highly mobile schools. The limited bait availability frequently thwarts the development of pole and line fishing.

In the Izu Islands region, skipjack fishing is highly seasonal. Although skipjack can be caught in this area throughout the year, most catches are made in spring and northern summer. In the period $1982 \sim 1989$, the highest total catch of 25,030.1 tons was in May. Skipjack catches taken in the Izu Islands region consist predominantly of fish with a body weight of less than $2.4 \mathrm{~kg}$. Schools of skipjack of the two groups appear together in all areas of fishing, but the catch proportions of the two groups tend
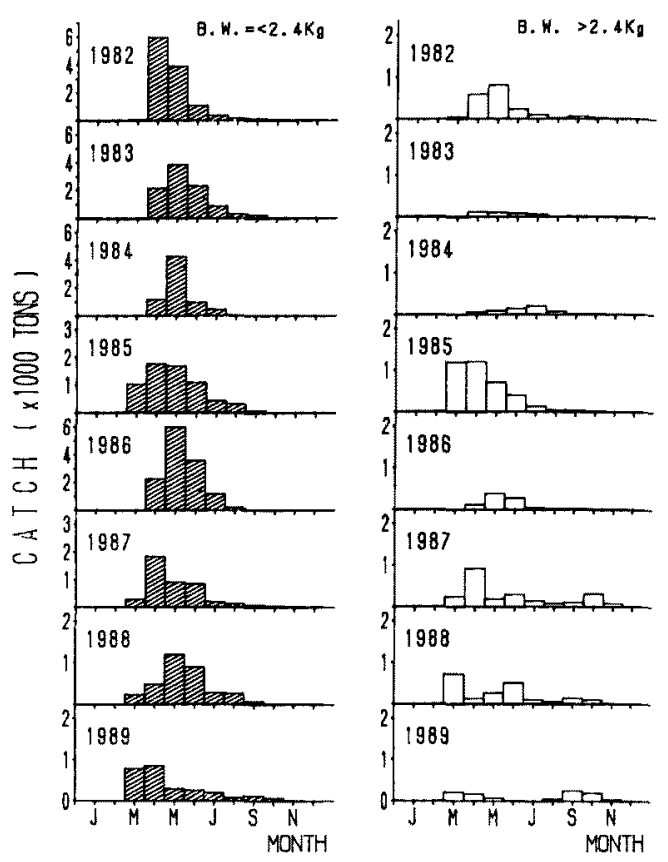

Fig. 1. Monthly total of skipjack catches in Izu Islands regions, 1982-1989.

to differ by month. Monthly changes in the catches for the small size group tend to increase from January to May and then to decrease from June to December. But, for the large size group, although the catches are high in spring and autumn, the pattern tends to differ with time. The highest total catch for the large size group was

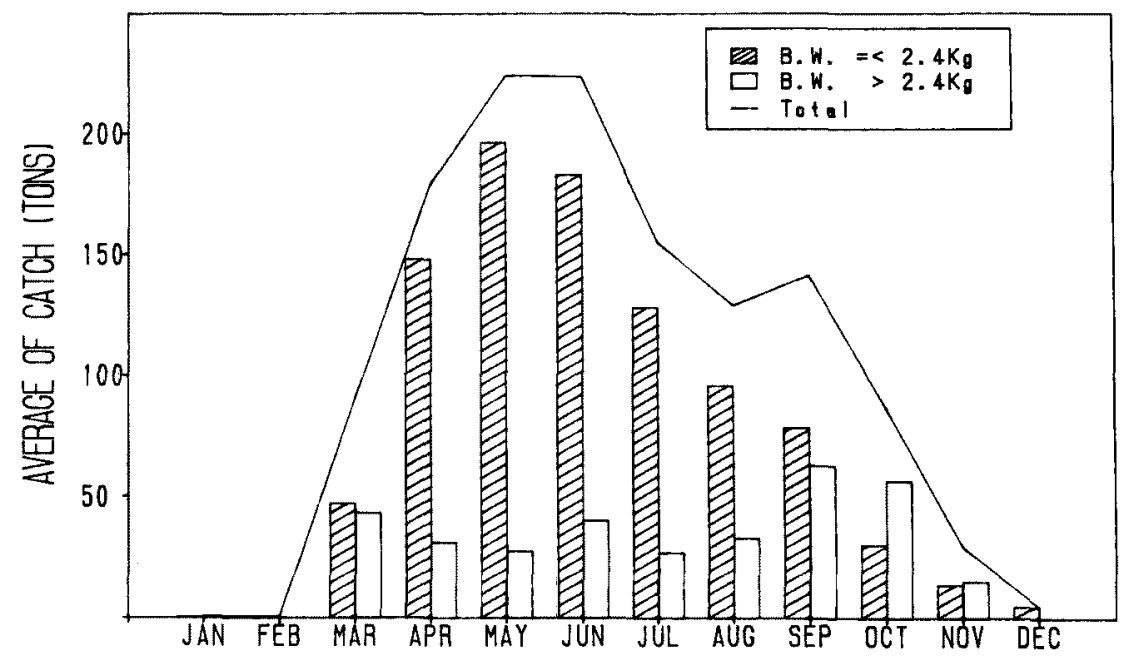

Fig. 2. Monthly average of skipjack catches for each body weight in Izu Islands regions, 1982-1989. 


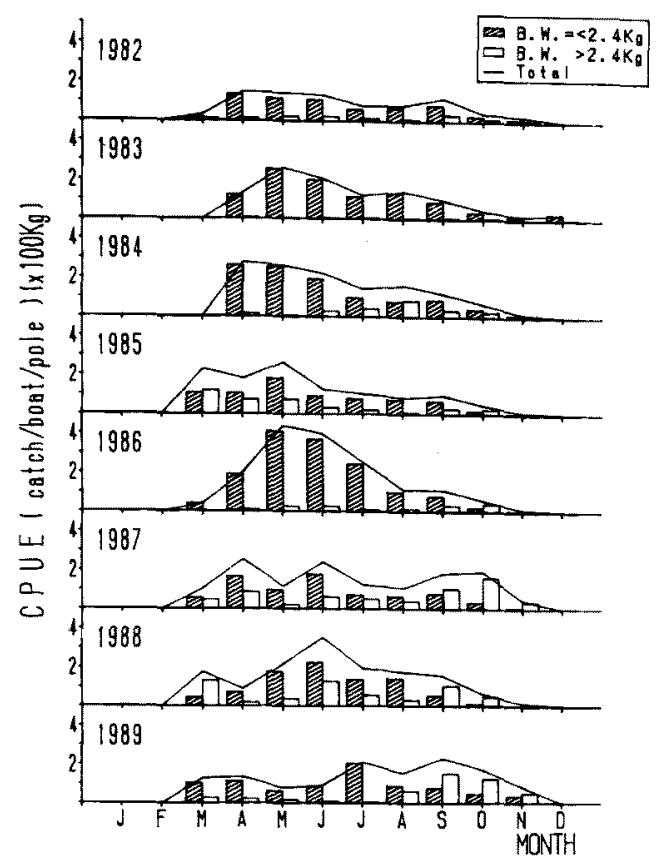

Fig. 3. Monthly catch per pole for skipjack in Izu Islands regions, 1982-1989.

3,374.1 tons in April, while for the small size group the highest total catch was $22,335.8$ tons in May. Generally, the catch tends to increase from January to May and to decrease from June to December. Also, skipjack catches fluctuated annually with the best catch of $14,434.4$ tons in 1986 and the poorest of $3,797.8$ tons in 1989 (Fig. 1).

The relationship between skipjack catches and fishing effort shows that monthly averages of catch per pole increased from January to June and then decreased until August. The catch increased in September then decreased again through December (Fig. 2). One reason for the increased landings in this area is the increase in the number of Japanese live bait boats conducting fishing operations in the region. Japanese pole and line boats concentrate their operations around the Izu Islands in April May. Ninety percent $(90 \%)$ of pole and liners belong to the class of less than 100 tons.

The CPUE used in this study is based on catches per pole. The CPUE in the Ist and 2nd quarters (January $\sim$ June) was higher than in the 3rd and 4th quarters (July $\sim$ December) of the year. For the large size group, the CPUE in the 3 rd and 4 th quarters seems to be higher than in
Table 1. Percentage of the skipjack catches by the body weight in Japanese waters, 1982-1989

\begin{tabular}{lcc}
\hline \multicolumn{1}{c}{ Fishing Ground } & $\begin{array}{c}\text { B.W. } \\
\text { (small size } \\
\text { group) }\end{array}$ & $\begin{array}{c}\text { B.W. }>2.4 \mathrm{~kg} \\
\text { (large size } \\
\text { group) }\end{array}$ \\
\hline Tainan f.g. & 39.1 & 60.9 \\
Okinawa f.g. & 52.9 & 47.1 \\
Satsunan f.g. & 46.1 & 53.9 \\
Southern Kinan f.g. & 54.9 & 45.1 \\
Northern Kinan f.g. & 75.3 & 24.7 \\
Ogasawara f.g. & 42.1 & 57.9 \\
Izu f.g. & 81.6 & 18.4 \\
Southern Tohoku f.g. & 58.2 & 41.8 \\
Northern Tohoku f.g. & 76.0 & 24.0 \\
\hline
\end{tabular}

the 1 st and 2 nd quarters of the year. On the contrary, the CPUE for the small size group in the 3rd and 4th quarters are lower than in the 1 st and 2nd quarters of the year (Fig. 3).

Fig. 4 shows changes in catch distribution during the period from January 1982 to December 1989 . About $82 \%$ of the estimated catch of $73,355.3$ tons consisted of small group fish. In comparison with other areas, the Izu region has the highest catch in percentage terms for the small size group (Table 1.). The percentage of the large size group in the 1st quarter, in the second half of the 3 rd quarter, and in the 4 th quarter was high, while it was low in the 2 nd quarter and the first half of the 3rd quarter. Also the percentage of the small size group was high from the 2 nd through the 3 rd quarter of the year. Table 1 also shows that the high percentage of catches for the large size group did not continue in February when the large size group was mainly caught in southeastern areas. The catch of the large size group increased again in March. Similarly, a good occurrence of the large size group was also found in the vicinity between lat. $30^{\circ} \mathrm{N}$ and lat. $35^{\circ} \mathrm{N}$ in September $\sim$ November, when the schools moved south and southwestward.

\section{Discussion}

There are three ways by which skipjack schools migrate to the Izu Islands region; 1) from Satsunan and Kinan areas in the 2 nd and 3 rd quarters; 2) from the Ogasawara region in the 1st through the 3rd quarter; and 3) from the Tohoku area when the skipjack schools move southwestwards through the 4 th quarter of the year. ${ }^{1)}$ There are two groups of skipjack in the Izu Islands region which differ in both body size and habits. One group only migrates up and down along the 

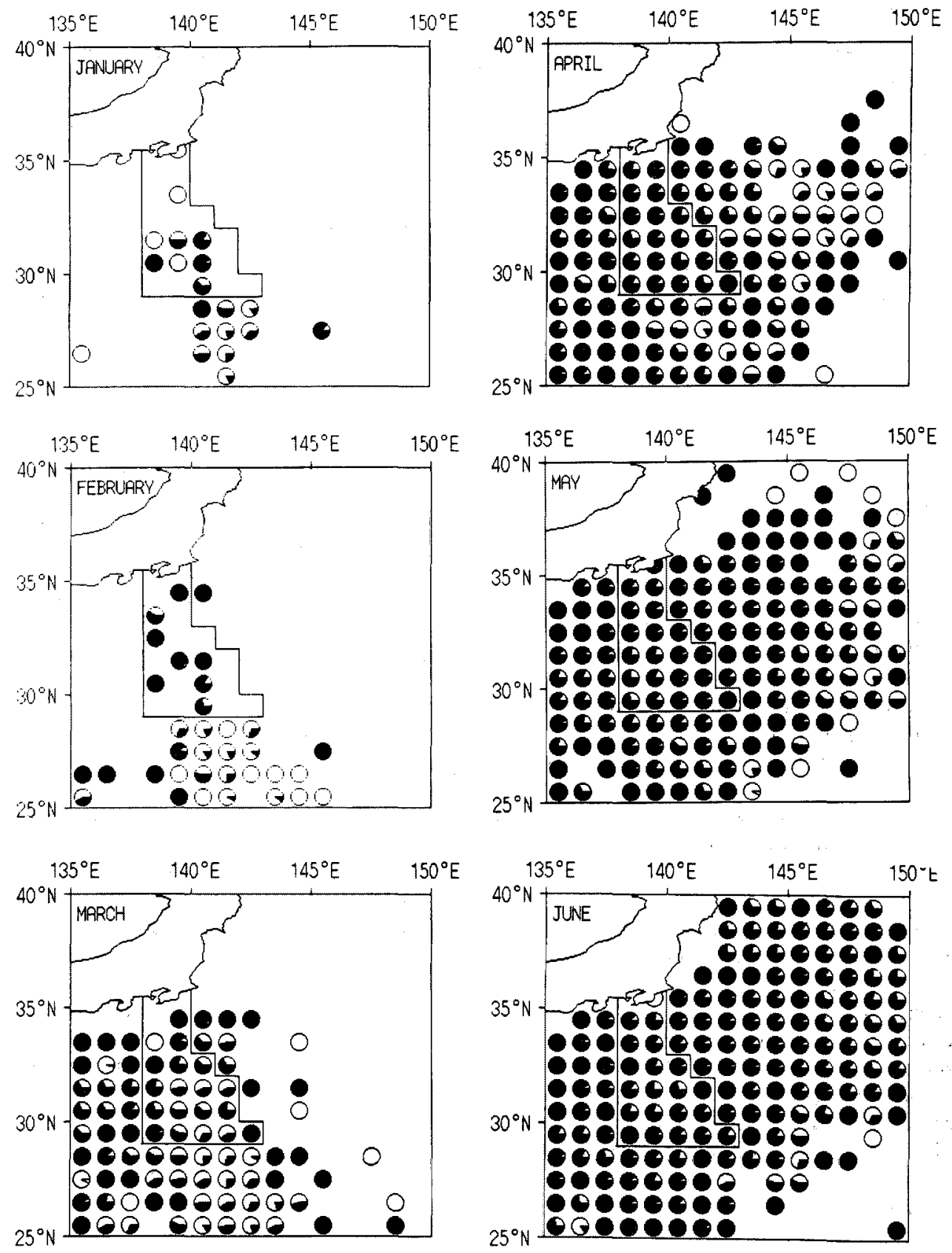

Fig. 4, Distribution of Percentage of size composition of skipjack caught from Northwestern Pacific Ocean, 1982-1989.

The line represent limits of range of the Izu Islands regions (๑: B.W. $\leqq 2.4 \mathrm{~kg}$, O: B.W. $>2.4 \mathrm{~kg}$ ). 

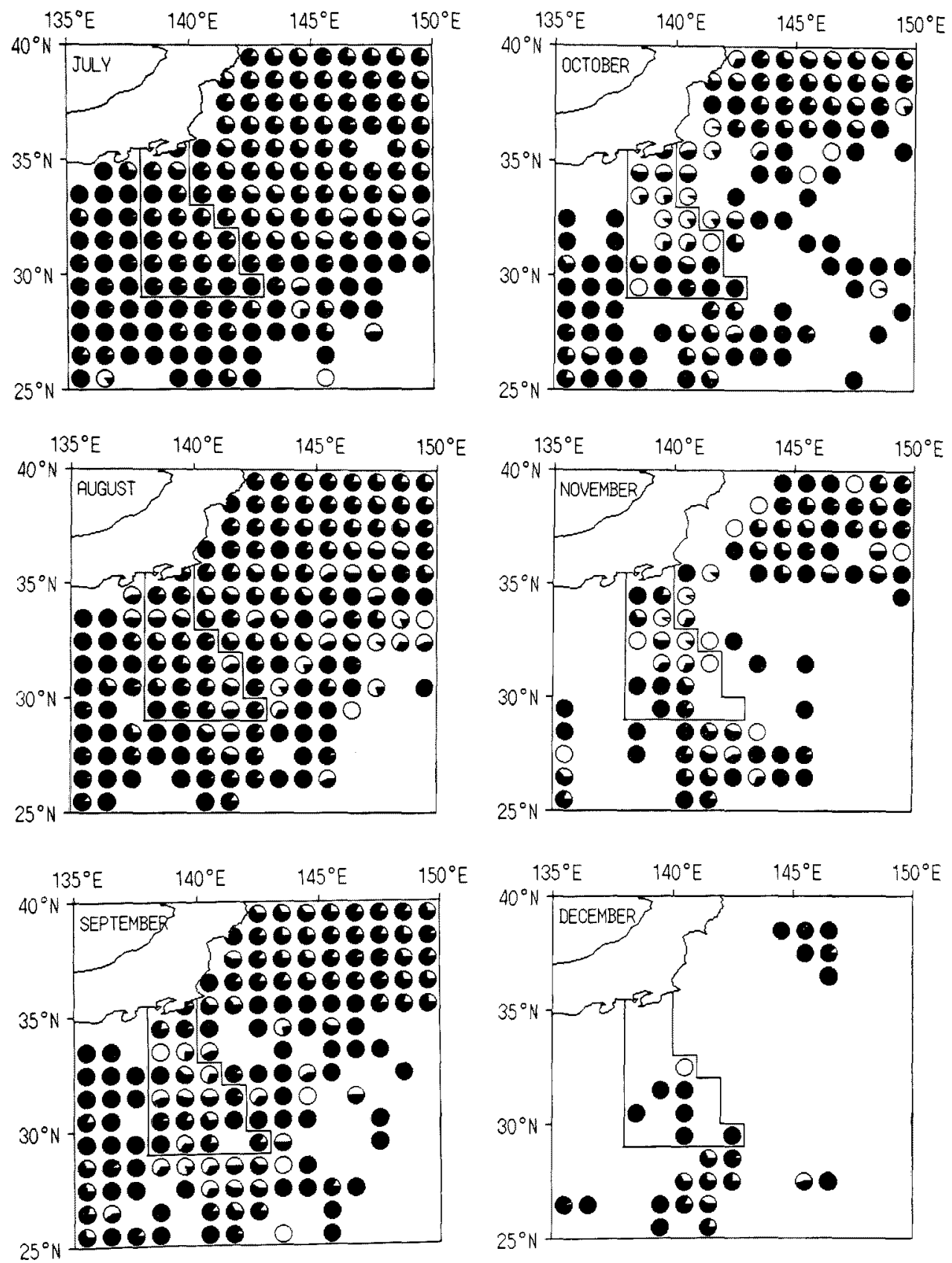

Fig. 4. continued. 

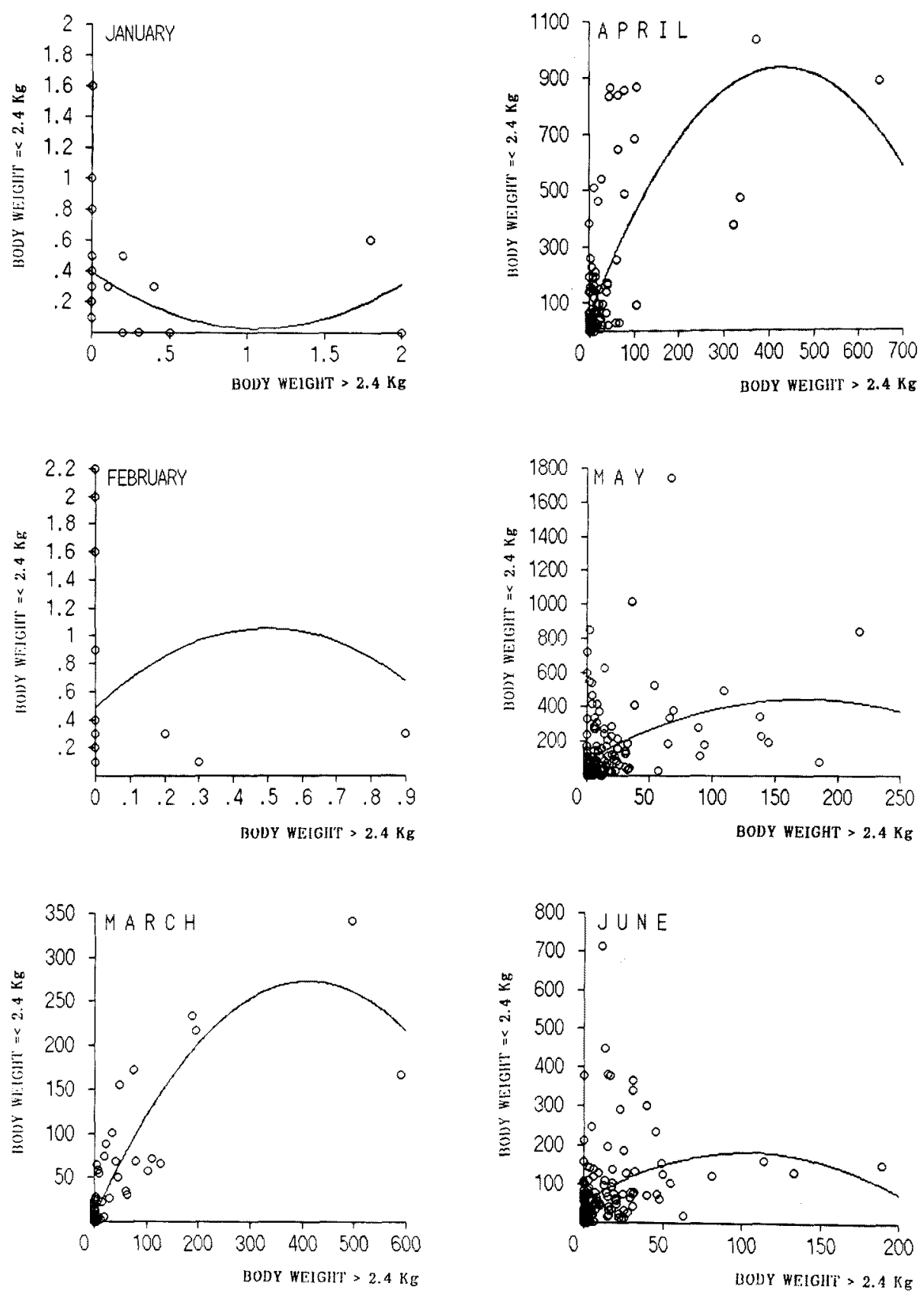

Fig. 5. Trend in size composition of skipjack catches taken in Izu Islands regions, 1982-1989. Plots of the small size group catches (tons) against the large size group for each area fished. 

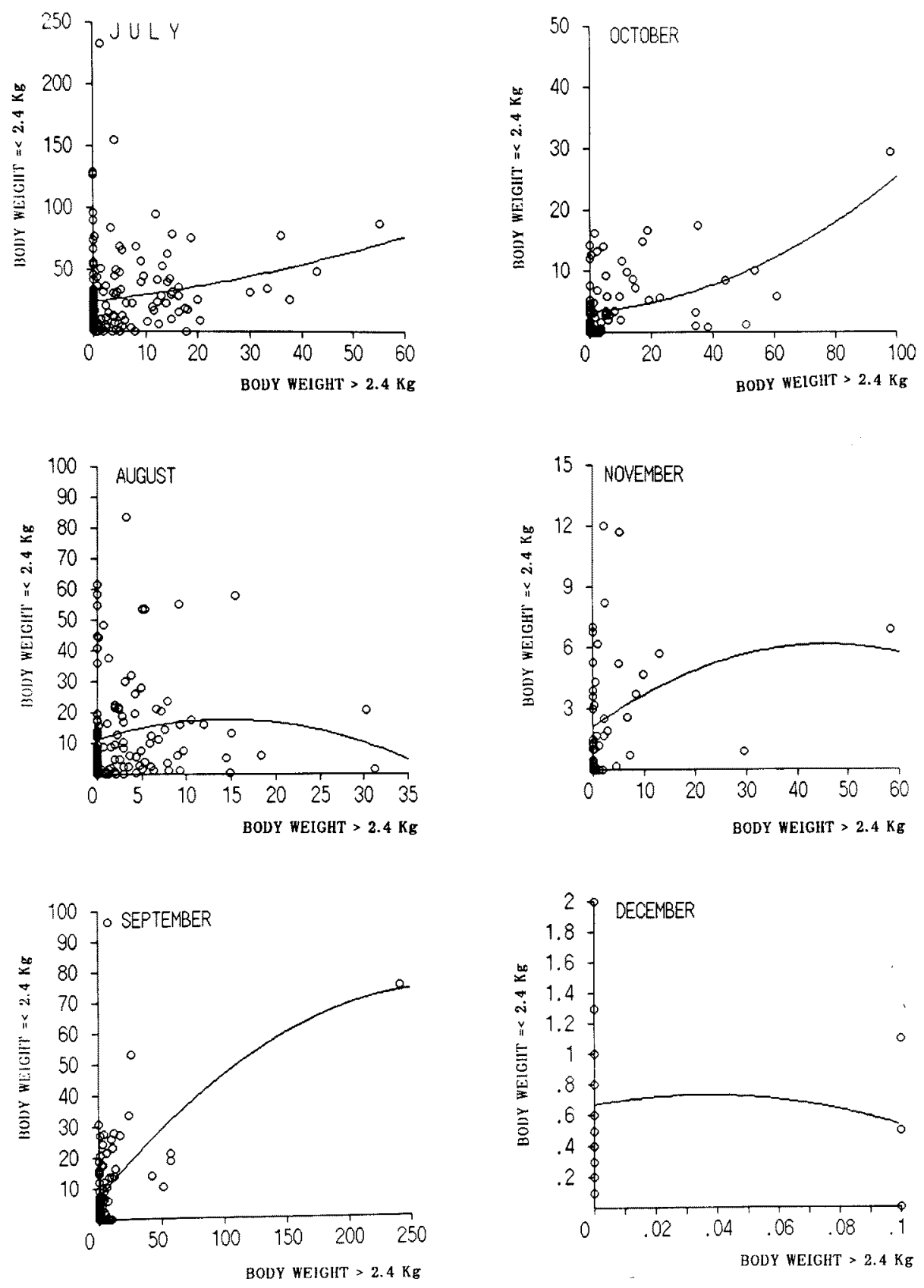

Fig. 5. continued. 
Izu-Bonin Chain. It is composed chiefly of 3and 4-year-old groups. The other is the migratory group which migrates to the northeastern regions. This consists mainly of 2- and 3-year-old groups. ${ }^{33}$ In Japanese waters, the 2-year-old group of skipjack consists of fish with a body length between 40 and $50 \mathrm{~cm} .{ }^{22}$ A skipjack which is about 50 $\mathrm{cm}$ in body length is about $2.4 \mathrm{~kg}$ in body weight. ${ }^{\text {) }}$ Based on the above fact, we define the small size group as consisting of skipjack with a body weight of $\leqq 2.4 \mathrm{~kg}$ and an age of less than 2 years old. The large size group consists of skipjack with a body weight of $>2.4 \mathrm{~kg}$ and an age of 3 years old or more.

As noted, the northeastward movement of skipjack fishing grounds along the coast of Japan begins in March while the southwestward movement begins in early September every year. It can be seen in Fig. 4 that in January through February the skipjack catch distribution area is mainly concentrated in the Ogasawara and Izu Islands regions. Throughout the period, the skipjack, especially those of the large size group, moved to avoid the low temperature waters of the north, to feed and spawn in warmer waters. The catch of the small size group for January and February makes up about $57 \%$ and $85 \%$ of the total catch, respectively. The catch of the small size group mainly consists of 2-year-old fish, while the large size group consists 3-year-old fish. Both size groups are also caught in the Izu Islands region when they migrate southwards for feeding. The 2-year-old group appears in the northeastern area in August, and during southward migration this age group passes the Izu area together with the 3-year-old group. ${ }^{\text {.) }}$

The possible reasons for northerly migration in March are due to the rising of water temperature in the north and the gradual extension of the Japan Current to the north. Also, the region and its vicinity cause the fish to migrate to the area for feeding. During spring and summer, about $82 \%$ of pole and line catches involve the small size group. This group could be caught in the Izu region as they migrate along the BoninNorthern Kinan-Izu Chain to reach the Tohoku region for feeding.

Although only a small percentage of the catch, the large size group were also caught during the period as they migrated to feed and spawn. Kawasaki $^{3>}$ has noted that the 4-year-old group migrates to the Izu Islands region from April to May, while the 3-year-old group stays in the Izu
Islands region from April to October. By catch pattern, from March to May perhaps the large size group consists of 3- and 4-year-old groups while the 3-year-old group is dominant from June to August.

From September through November, the percentage of the catch of the large size group increased, and then it decreased in December. The high catch during the period is due to the southwestward migration of the large size group from Tohoku to the Izu Islands region for spawning. Bigger catches of the large size group are generally attained from October to November. Because the 4-year-old group migrates earlier to the Izu region from April to May, it is reasonable to mention that the large size group is as the 3 years old group. In relation to the evidence, some researchers have recognized that the spawning activity of skipjack in the Izu Island regions is in September. ${ }^{52}$ Skipjack showing a moderate increase in the modal length from $41 \mathrm{~cm}$ in early April to $51 \mathrm{~cm}$ in late October are dominant in the Izu region. Also, large size skipjack of 57 $\mathrm{cm}$ in length are found in late April and $66 \mathrm{~cm}$ in length in late October. The spawning area spreads east and south in the 3rd and 4th quarters, and is diffused in the 1st quarter. ${ }^{6)}$ Matsumoto $^{\text {? }}$ has found that large skipjack are concentrated in the northwestern Pacific Ocean, to the south and east of Japan. The size at first maturity of skipjack is approximately $45 \mathrm{~cm}(2.4 \mathrm{~kg}) .^{6,8)}$ In the Izu Islands region, the center of fishing for skipjack moves progressively to the north from spring until summer and southward from autumn to winter. This is a fairly good indication that the skipjack schools have migratory tendencies.9, 10) The small size groups were the dominant catches in this region. The 2-year-old group of skipjack occurs in shoal areas of the Izu Islands region, with some spawning also in summer. ${ }^{11}$ The size composition of catches in the Izu Islands region is shown in Fig. 5. The result shows that generally there is a positive relationship between the catch of both groups caught by Japanese skipjack pole and line fleets. Although there is a tendency for increases in the catch for the small size group to be followed by an increase for the large size group, the composition of both groups differ with time. During the northern spring, the large size group consist of both 3and 4-year-old fish. In any case, only 3-year-old skipjack will be caught when fishing operation is conducted from summer to winter. Assuming 
that the 2-year-old group that is caught in autumn through winter belong to the same group that had earlier migrated to the north in the spring and the summer, the catch composition will differ. Due to increments in the size of the skipjack, the skipjack caught in the autumn-winter are thus bigger than the catches in spring-summer. Skipjack spawn more than once in a season, because more than one mode of advanced oocytes are found in active ovaries. ${ }^{12)}$ Skipjack are multiple spawners, spawning several times during a season. The skipjack that migrate into Japanese coastal waters are probably fish that originate in northern summer spawning. ${ }^{11}$ Skipjack caught in Japanese waters by bait boats are usually fish schools associated with birds with sizes ranging from $20 \mathrm{~cm}$ to $80 \mathrm{~cm}$ with modes at $32,45,58,67$, and $75 \mathrm{~cm}$. The fish schools associated with banks had a range of $42-62 \mathrm{~cm}$ and a single mode at $49 \mathrm{~cm}$. Whereas, the skipjack which were with floating debris associates had a range of 25-61 $\mathrm{cm}$ and modes at 34 and $52 \mathrm{~cm}$. Meanwhile, those associated with shark and whales had a range of 33-61 cm and a mode at 50 and possibly $40 \mathrm{~cm}^{13)}$

The skipjack caught in the Izu Islands region by Japanese pole and line fleets consisted of a wide range in size, depending on the fishing season. Furthermore, in the Izu Islands region, skipjack can be caught throughout the year while the peak season occurs from April to July. Moreover, recently, although the skipjack taken by Japanese skipjack pole and line fleets have been decreasing in number, the size composition moves similarly.

\section{Acknowledgments}

We are grateful to the staff of Tohoku National Fisheries Research Institute, Resources Manage- ment Division for permission to use the data which be described in this paper.

\section{References}

1) K. Fujino: Range of the skipjack tuna subpopulation in the Western Pacific Ocean. Proc. of the 2nd CSK Symposium, Tokyo, 1970. Comnercial Fisheries Review, 14, 373-384 (1972).

2) T. Kawasaki: Population structure and dynamics of skipjack in the north Pacific and its adjacent waters. Bull. Tohoku Reg. Fish, Res, Lab., 24, 28-47 (1964).

3) T. Kawasaki: On the migration and the growth of the skipjack, Katsuwonus pelamis, in the Izu and Bonin sea areas and the northeastern sea area along the Pacific coast of Japan. Bull. Tohoku Reg. Fish. Res. Lab., 4, 101-119 (1955).

4) T. Kawasaki: The growth of skipjack on the northeastern sea of Japan. Bull. Tohoku Neg. Fish. Nes. Lab., 23, 44-60 (1963).

5) M. YAO: Growth of skipjack tuna in the western Pacific Ocean. Bull. Tohoku Reg. Fish. Res. Lab., 41, 71-82 (1981).

6) P.N. Sund, M. Blackburn, and F. Williams: Tunas and their environment in the Pacific Ocean: A Review. Oceamogr. Mar. Bio. Ann. Rev, 19, 443-512 (1981).

7) W. M. Matsumoto: Distribution, Relative abundance and movement of skipjack tuna, Katsuwonus pelamis, in the Pacific Ocean based on japanese tuna long line catches, 19641967. NOAA Technical Report NMFS SSRF-695, 1-30 (1975).

8) R. E. Kearney: The stock structure of skipjack resources and the possible implications on the development of skipjack fisheries in the central and western Pacific. F.A.O. Fisheries Technical Paper, 144, 57-69 (1975).

9) F.C. Cleaver and B. M. Shimada: Japanese skipjack (Katsuwonus pelamis) fishing methods. Commercial Fisheries Review, 12, 1-27 (1950).

10) Muhammad Zainuri, M. Nemoto, and S. Takeuchi: Catch and effort analysis of japanese pole and line fisheries for skipjack tuna, Katsuwonus pelamis. Journal of the Tokyo University of Eisheries, 79, 87-93 (1992).

11) T. Kawasaki: The skipjack tuna resource. Marine Fisheries Review, 15, 1-7 (1973)

12) J. R. Hunter, B. J. Macewicz, and J. R. Sibert: The spawning frequency of skipjack tuna, Katsuwonus pelamis, from the south Pacific. Fishery Bull., 84, 895-902 (1986).

13) W. M. Matsumoto, R. A. Skillman, and A. E. Dizon: Synopsis of biological data on skipjack tuna, Katsuwonus pelamis. NOAA Technical Report NMFS Circular 451, 1$92(1984)$. 